\title{
WADEM Climate Change Position Statement
}

\author{
The World Association for Disaster and Emergency Medicine
}

Below is the World Association for Disaster and Emergency Medicine's (WADEM's) Position Statement on Climate Change adopted by the Board of Directors on April 24, 2017 in Toronto, Canada:

Climate change is affecting disaster risk and disaster impact. WADEM recognizes climate change as an issue of global concern. It is WADEM's responsibility to support the capacity of emergency management, humanitarian, and health professionals to address the disaster impacts of climate change.

WADEM supports health improvement activities, with emphasis on health promotion during and following a disaster with emphasis on reducing the effects of climate change, achieved by cooperation among and between multidisciplinary professions involved in research, education, management, and practice in prehospital, emergency, public health, and disaster health care.

The United Nations General Assembly has encouraged the Intergovernmental Panel on Climate Change to continue to assess the adverse effects of climate change upon communities and recognizes the need for implementation of disaster risk reduction programs. ${ }^{1}$ The Special Report on Managing the Risks of Extreme Events and Disasters to Advance Climate Change Adaptation ${ }^{2}$ and the Fifth Assessment Report produced by the Intergovernmental Panel on Climate Change ${ }^{3}$ provide an updated review of scientific knowledge relevant to climate change and reported consensus on emerging risks associated with climate change; as such, it represents an emerging threat to the health status of communities. Impact categories identified by these reports relative to disaster risk include:

- Increased morbidity and mortality due to extreme heat waves, fire, and other extreme weather events;

References

1. United Nations General Assembly Resolutions on Natural Disasters and Vulnerability (59/233 and 58/215).

2. IPCC. Managing the Risks of Extreme Events and Disasters to Advance Climate Change Adaptation. Intergovernmental Panel on Climate Change [Core Writing Team: Field CB, Barros V, Stocker TF, et al]. IPCC; Geneva, Switzerland; 2012:582pp.

3. IPCC. Climate Change 2014: Synthesis Report. Contribution of Working Groups I, II, and III to the Fifth Assessment Report of the Intergovernmental Panel on Climate Change [Core Writing Team: Pachauri RK and Meyer LA (eds.)]. IPCC; Geneva, Switzerland; 2014:151pp.
- Biodiversity changes leading to infectious disease spread and duration due to alterations in weather and vector distribution;

- Reduced food yields due to drought;

- Increased displacement of populations; and

- Increased risk of conflict, poverty, and economic shock.

The Lancet Countdown on tracking progress on health and climate change is an international, multidisciplinary research collaboration which aims to track the health impacts of climate hazards, health resilience and adaptation, health co-benefits of climate change, and calls for mitigation and broader political engagement. $^{4}$

The Sendai Framework for Disaster Risk Reduction (20152030), a 2015 UN landmark agreement, outlines priorities for action while identifying climate change as both a driver of disaster risk and as an influencing factor of disaster impact and sustainable development. ${ }^{5}$ As a result, WADEM:

- Recognizes the importance of climate change due to its influence on frequency and severity of natural hazards, and on disasters of natural, public health related, and conflict causes; and

- Recommends all disaster and emergency professionals and organizations adopt a risk-based approach to emergency planning that prepares for and enhances resilience to climate change effects and recommends linking this to the implementation of the Sendai Framework for Disaster Risk Reduction (2015-2030).

4. Watts N, et al. The Lancet Countdown: Tracking Progress on Health and Climate Change. Lancet. 2017;389(10074):1151-1164.

5. United Nations General Assembly. Sendai Framework for Disaster Risk Reduction 2015-2030. A/RES/69/283: 2015.

doi:10.1017/S1049023X17006823 